\title{
Zika Virus Transmission Through Blood Tissue Barriers
}

\author{
Svetlana F. Khaiboullina ${ }^{1,2}$, Fabiola M. Ribeiro ${ }^{3}$, Timsy Uppal ${ }^{1}$, Ekaterina V. Martynova ${ }^{2}$, \\ Albert A. Rizvanov ${ }^{2}$ and Subhash C. Verma ${ }^{1 *}$ \\ ${ }^{1}$ Department of Microbiology and Immunology, Reno School of Medicine, University of Nevada, Reno, Reno, NV, \\ United States, ${ }^{2}$ Department of Exploratory Research, Scientific and Educational Center of Pharmaceutics, Kazan Federal \\ University, Kazan, Russia, ${ }^{3}$ Department of Biochemistry and Immunology, Universidade Federal de Minas Gerais, Belo \\ Horizonte, Brazil
}

The recent Zika virus (ZIKV) epidemic in the Americas and the Caribbean revealed a new deadly strain of the mosquito-borne virus, which has never been associated with previous outbreaks in Asia. For the first time, widespread ZIKV infection was shown to cause microcephaly and death of newborns, which was most likely due to the mutation acquired during the large outbreak recorded in French Polynesia in 20132014. Productive ZIKV replication and persistence has been demonstrated in placenta and fetal brains. Possible association between ZIKV and microcephaly and fetal death has been confirmed using immunocompetent mouse models in vitro and in vivo. Having crossed the placenta, ZIKV directly targets neural progenitor cells (NPCs) in developing human fetus and triggers apoptosis. The embryonic endothelial cells are exceptionally susceptible to ZIKV infection, which causes cell death and tissue necrosis. On the contrary, ZIKV infection does not affect the adult brain microvascular cell morphology and blood-brain barrier function. ZIKV is transmitted primarily by Aedes mosquito bite and is introduced into the placenta/blood through replication at the site of the entry. Also, virus can be transmitted through unprotected sex. Although, multiple possible routes of virus infection have been identified, the exact mechanism(s) utilized by ZIKV to cross the placenta still remain largely unknown. In this review, the current understanding of ZIKV infection and transmission through the placental and brain barriers is summarized.

Keywords: ZIKV, ZIKV transmission, blood tissue barriers, placenta, microcephaly

\section{EPIDEMIOLOGY}

For decades, Zika virus (ZIKV) sporadic outbreaks have been registered in several countries in Asia, and the infection has been characterized by mild symptoms, where up to $80 \%$ of cases remain asymptomatic (Duffy et al., 2009). However, the 2014 outbreak in the South/Central Americas and the Caribbean opened a new chapter in ZIKV epidemiology, where neurological complications were demonstrated in adults and newborns (Triunfol, 2016; Roze et al., 2017; Lowe et al., 2018). The most alarming news was that nearly $10 \%$ of ZIKV infection cases were reported to cause microcephaly or fetal death (CDC, 2017) with devastating impact on families and communities of infected individuals (de Oliveira et al., 2017). Targeting the fetal brain tissues and death of neural progenitor cells (NPCs) by ZIKV has been confirmed in several research studies using immunocompetent animal models (Dong and Liang, 2018). ZIKV neurotropism seems to be quite puzzling since neuropathology has never been a characteristic associated with earlier outbreaks 
in South East Asia and Africa (Lim et al., 2017). It now appears that a single mutation (serine to asparagine, S139N) in the viral precursor membrane protein (prM) made the relatively mild virus to a more pathogenic and deadlier strain (Yuan et al., 2017). It has been suggested that this mutation arose during the 2013 ZIKV outbreak in Polynesia (Yuan et al., 2017). The association between microcephaly and prM mutation was further confirmed in a retrospective study, where clusters of microcephaly cases were identified in French Polynesia during the ZIKV outbreak (Cauchemez et al., 2016; Baud et al., 2017). In addition to the mutation in ZIKV genome, socioeconomic condition was also suggested to contribute to the development of microcephaly (Franca et al., 2018; Souza et al., 2018). Analysis of the spatial distribution revealed that the majority of microcephaly was diagnosed in economically deprived areas, while only $2 \%$ of cases were located in the wealthiest district (Souza et al., 2018). Therefore, it could be suggested that mutation in ZIKV genome combined with other factors could contribute to the development of microcephaly.

The first ZIKV strain was isolated from non-human primates in 1947 from sylvatic mosquitoes in 1948 (Dick, 1952). Since, only a few human cases were reported after ZIKV discovery, virus was not considered a public health threat (Macnamara, 1954) until 2007, when the first ZIKV epidemic was reported in Micronesia (Duffy et al., 2009) where nearly $73 \%$ of the inhabitants were reported to be infected. This outbreak was followed by another large epidemic in French Polynesia (2013-2014, Cao-Lormeau et al., 2014). The most disturbing features of these outbreaks were microcephaly and Guillain-Barre Syndrome (GBS) linked to ZIKV infection (Cao-Lormeau et al., 2016; Cauchemez et al., 2016; Johansson et al., 2016). Cao-Lormeau et al. (2016) suggested that the pathogenesis of GBS is complex, including HLA allele genotype, autoantibodies and unknown neurotoxic factors. Later, GBS cases were reported during the outbreak in several South American countries, supporting the link between ZIKV infection and the disease (European Centre for Disease Prevention, and Control, 2016). GBS is an inflammatory neurological disease, which is associated with the post-infection nerve injury (Wijdicks and Klein, 2017). The pathogenesis of GBS remains largely unknown; however, it appears that ZIKV infection often triggers the onset of the disease (Wijdicks and Klein, 2017).

In a short duration, ZIKV crossed the Pacific Ocean, reaching the South America in 2014 (Lowe et al., 2018). An outbreak in Brazil was followed by reports of several ZIKV infection cases in numerous South American countries (Heukelbach et al., 2016; Pan American Health Organization World Health Organization, 2016). By the year 2017, approximately 217,000 confirmed ZIKV cases were reported to the Pan-American Health Organization (PAHO, 2016). It appears that ZIKV epidemic reached its peak in 2016, when a large number of suspected/confirmed ZIKV cases were reported (PAHO, 2017). However, in 2016, ZIKV incidence declined in all South American countries (PAHO, 2017). A similar pattern of ZIKV epidemic has been observed in the United States, where the highest number of ZIKV cases $(5,168$ symptomatic diseases) were documented in the year
2016 (CDC, 2016). However, ZIKV infection reports declined in 2017, when only 452 cases were documented. Even fewer ZIKV infections were confirmed by August of 2018 (34 cases).

Like many Flaviviruses, ZIKV is transmitted by infected Aedes species mosquitoes (Aedes aegypti and Aedes albopictus), which are present across the large territories including Africa, South/South-East Asia, and South/North America. The distinct feature of $A$. aegypti is that they feed almost exclusively on humans and usually rest indoors (Scott and Takken, 2012; Kraemer et al., 2015). It is believed that factors, such as human activities and climate changes, contribute to geographical expansion of mosquitoes/virus currently spread-out in Europe, United States, and South America (Medlock et al., 2012; Carvalho et al., 2014).

Zika virus emerges in regions also known to be endemic for Dengue virus (DENV) (Rigau-Pérez et al., 1998). Also, ZIKV was shown to have structural homology with DENV (Sirohi et al., 2016; Prasad et al., 2017), which could explain high antibody cross reactivity (Lanciotti et al., 2008; Duffy et al., 2009; Stettler et al., 2016). Antibody cross reactivity plays role in DENV pathogenesis and is linked to dengue hemorrhagic fever and fatality (Guzman et al., 1987). Therefore, it was suggested that flaviviridae antibody cross reactivity could play role in pathogenesis of ZIKV. However, data on the role of the cross-reactive antibodies in ZIKV pathogenesis is controversial. Brown et al. (2019) have demonstrated that this cross reactivity plays a role in enhancing the severity of ZIKV infection. Using an animal model, Brown et al. (2019) have demonstrated that DENV antibodies could increase placental damage, fetal growth restriction, and fetal resorption. These data suggest the detrimental role of antibody cross reactivity in the recent ZIKV outbreak in South America. In contrast, studies have shown that flaviviruses could induce a cross protective immune response. For example, Grifoni et al. (2017) have demonstrated that previous DENV infection could elicit memory $\mathrm{T}$ cells recognizing ZIKV peptides. Authors suggested that prior DENV exposure could protect against ZIKV infection by affecting the timing, magnitude, and quality of the $\mathrm{T}$ cell response. Additionally, Ribeiro et al. (2018) suggested that ZIKV crossreacting antibodies may protect against DENV, as a significantly decreased frequency of DENV infection was documented after ZIKV outbreak in South America. Therefore, co-circulation of two flaviviruses sharing multiple immunogenic epitopes could affect the epidemiology of each virus; although the outcomes of the immunological cross reactivity in ZIKV and DENV remain to be determined.

\section{GENOMIC STRUCTURE}

The first ZIKV strain was isolated in 1947 from a sentinel monkey in Zika forest in Uganda, Africa (Dick et al., 1952). Later, many new strains were identified which are divided into two major lineages: African and Asian (including South American) (Haddow et al., 2012; Gong et al., 2016). The origin of these two lineages is still debated. It was suggested that both ZIKV lineages originated from the strain isolated in Uganda in 1947 
(Yokoyama and Starmer, 2017). However, Gong et al. (2016) proposed that the African strains diverged to produce distinct African and Asian lineages.

Zika virus is a member of the Flavivirus family, which also includes several human pathogens such as West Nile Virus (WNV), DENV and Yellow Fever Virus (YFV). Kostyuchenko et al. (2016) have shown that structurally ZIKV is similar to DENV and WNV. However, ZIKV is a thermally stable virus compared to DENV and its stability at $40^{\circ} \mathrm{C}$ is considered a key factor behind the epidemics in the temperate zones (i.e., Brazil/South America). ZIKV genome is composed of a positive single-stranded RNA, which is protected by the capsid and an envelope layers (Hasan et al., 2018) (Figure 1). The viral RNA is translated into a single polypeptide, which is cleaved into three structural proteins, (premembrane/membrane-prM/M, Envelope/E and Capsid/C) and seven non-structural (NS) proteins (NS1, NS2A, NS2B, NS3, NS4A, NS4B, and NS5) by viral and host proteases (Figure 2). The E protein binds to the receptor and fuses with the cell membrane. Sequence and structural analysis of ZIKV E protein revealed that some parts of the protein have a close resemblance to neurovirulent WNV and Japanese encephalitis viruses (JEV), while others are similar to DENV (Kostyuchenko et al., 2016). This may explain the neurological symptoms in ZIKV- infected patients as well as cross-reactivity between the members of Flaviviridae family. The $M$ protein is hidden under the $\mathrm{E}$ protein/layer. The mature $\mathrm{M}$ protein is released by cleavage of prM protein by furin in the Golgi (Schlesinger et al., 1989). The prM acts as a chaperone for the $\mathrm{E}$ protein during virion assembly (Roby et al., 2015). It was shown that a single mutation in the prM protein converted a relatively mild ZIKV strain into a teratogenic strain (Yuan et al., 2017).

Five NS proteins are encoded by viral RNA, where two of them (NS1 and NS4) are post- translationally cleaved making a total of seven NS proteins. Each NS protein plays a unique role in virus replication and evasion of the host immune

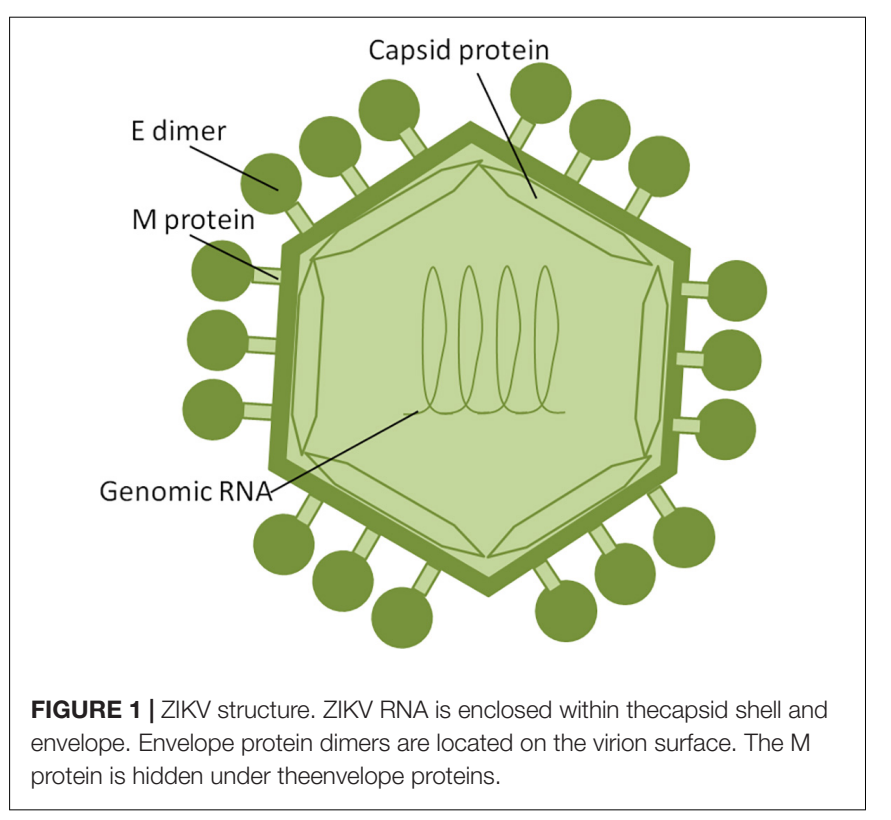

responses. NS1, a strong immunogen (Muller and Young, 2013), co-localizes with viral dsRNA and plays an important role in virus replication (Muller and Young, 2013) and interferonassociated antiviral defense (Xia et al., 2018). The NS2 and NS3 proteins are shown to play a crucial role during virion assembly (Leung et al., 2008; Sahoo et al., 2016). In addition, NS3 protein, together with NS2B protein, functions as a protease, RNA helicase, nucleotide triphosphatase, and RNA triphosphatase (Wengler et al., 1991; Warrener et al., 1993; Li et al., 1999; Yusof et al., 2000). The NS4 protein interferes with intracellular signaling and has been linked to autophagy and altered neurogenesis (Liang et al., 2016). The NS5 protein was shown to act as a methyltransferase, guanylyltransferase, and RNA-dependent RNA polymerase (Egloff et al., 2002; Ray et al., 2006; Dong et al., 2012).

\section{MODES OF TRANSMISSION}

\section{Cell Tropism}

Clinical presentations of ZIKV infection vary from mild skin rashes to severe brain damage and auto-immune disorder (Calvet et al., 2016), which could be attributed to the fact that ZIKV can target multiple cell types. Two receptors, AXL and TIM1, were suggested as candidates for ZIKV entry in vitro, while physiological relevance of these receptors is yet to be determined in vivo (Retallack et al., 2016; Tabata et al., 2016). Expression of AXL, a member of the TAM receptor family of cell surface receptor tyrosine kinases (Wu et al., 2014), has been linked to ZIKV entry in multiple cell types (Meertens et al., 2017). This receptor is expressed on various cells including keratinocytes, endothelial cells, and NPCs (Hamel et al., 2015; Nowakowski et al., 2016; Richard et al., 2017). It appears that the tyrosine kinase activity of AXL is important for viral entry in vitro (Liu et al., 2016). Interestingly, Richard et al. (2017) have shown that AXL-dependent infection of fetal endothelial cells is a unique feature of ZIKV infection that could explain virus tropism to fetus tissues. However, it appears that although AXL receptor is essential for ZIKV entry in vitro, its role in in vivo remains controversial. Hastings et al. (2017) demonstrated that susceptibility of ZIKV infection in $A x l^{-/-}$mice remains similar to that of wild type animals. Similarly, Wang et al. (2017) revealed that there is no difference in the survival rate, clinical manifestations, viral load and ZIKV distribution among $A x l$ mice and wild type control animals. Collectively, data suggest that AXL receptors are indispensable for ZIKV entry and other receptors may be involved as well.

Several cell types were shown to be susceptible to ZIKV infection, including endothelial cells, monocytes, skin keratinocytes, dendritic cells and NPCs (Hamel et al., 2015; Bowen et al., 2017; Devhare et al., 2017; Khaiboullina et al., 2017; Richard et al., 2017). Two independent comprehensive studies have demonstrated susceptibility of multiple cell types derived from lung, liver, skin, kidney, ovary, retina, prostate, muscle tissue, nervous tissue and testicular tissue to ZIKV infection (Chan et al., 2016; Himmelsbach and Hildt, 2018). While all of these cell types were found to be susceptible to 


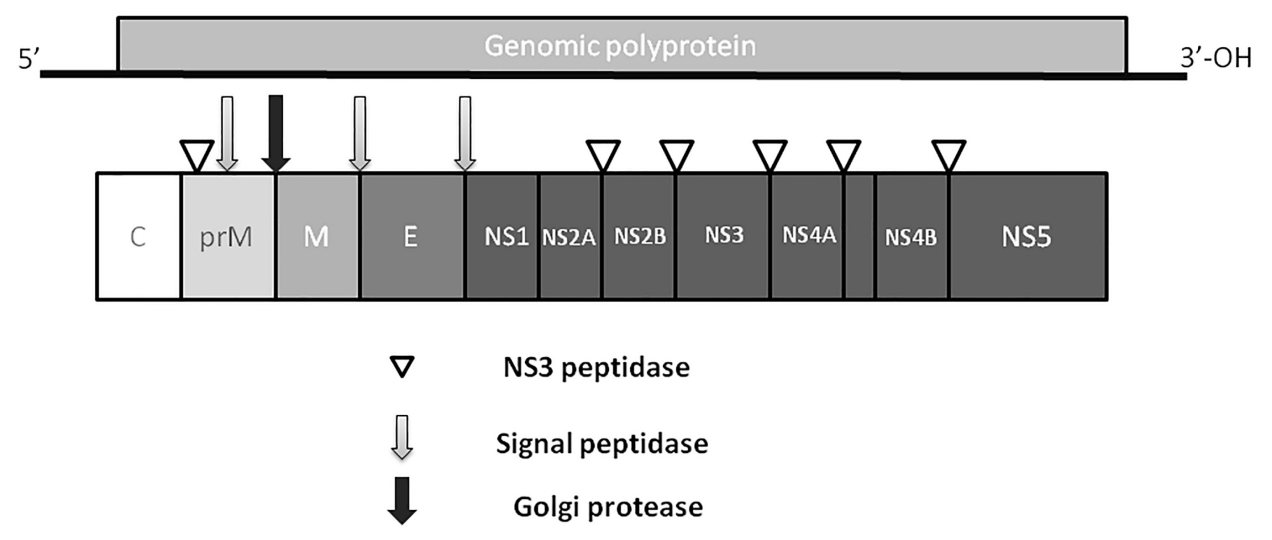

FIGURE 2 | ZIKV genome. Virus genome consists of monopartite, linear single stranded, positive sense RNA. RNA is translated into single polyprotein, which is post-translationally cleaved releasing three structural proteins, capsid (C), prM,envelope (E), and five non-structural proteins (NS1, NS2, NS3, NS4 and NS5). prM protein is cleaved by Golgi peptidase,releasing mature M protein and prM. Later, NS2 and NS4 are cleaved by NS3 to release NS2A, NS2B, NS4A and NS4B proteins.

ZIKV infection, virus replication was found to be the lowest in nervous tissue derived cells. Also, Chan et al. (2016) have shown that ZIKV replication is cytopathic in neuronal cells, which could explain the neurological damage in the fetus. In addition, cytopathic effect has been demonstrated in the placental, but not in prostatic, testicular and renal cell lines. Authors suggested that the cytopathic effect of ZIKV in placental cells could explain the teratogenic effect of the virus. Also, the lack of cytopathic effect, combined with the effective virus replication in prostatic and testicular cells, were suggested as key reasons for the virus shedding and sexual transmission in ZIKV-infected individuals.

Zika virus crosses placenta, reaching the fetus to target the neuronal tissue (Adibi et al., 2016). Therefore, identification of cells that support ZIKV replication in the placenta is especially important to understand the mechanisms utilized by the virus to cross the placenta and to further design anti-ZIKV drugs. Several cell types within the umbilical cord and placenta were shown to be susceptible to ZIKV infection (El Costa et al., 2016). Among the cell types studied, umbilical mesenchymal cells effectively supported virus replication (El Costa et al., 2016). Interestingly, these cells were able to facilitate the virus spread via cell-tocell contact, suggesting that binding to the receptor may not be the only way that virus spreads within the tissue. Additionally, decidual macrophages from placenta are also susceptible to ZIKV infection, supporting the data published by Quicke et al. (2016) demonstrating that placental macrophages are key players in ZIKV transmission.

Multiple studies have shown that endothelial cells support ZIKV infection and replication (Quicke et al., 2016; Papa et al., 2017; Roach and Alcendor, 2017; Alimonti et al., 2018; Peng et al., 2018). Endothelial cells are an essential component of the bloodtissue barrier controlling the leukocyte trafficking and solute permeability. It appears that ZIKV has limited effect on brain endothelial monolayer permeability in vivo (Papa et al., 2017). This data provides an explanation of the limited effect of ZIKV infection in the adult's brain, while mechanisms of virus spread to the fetal brain still remain elusive.
Zika virus can infect various populations of leukocytes. We have shown that ZIKV infects human monocytes (Khaiboullina et al., 2017). It appears that monocytes are the main leukocyte population harboring the virus in circulation (Michlmayr et al., 2017). Monocytes are a mobile population of leukocytes capable of traveling across the endothelium.

Monocytes trans-endothelial migration could contribute to the virus dissemination across the placenta, as has been shown for other viruses targeting the fetus (Arias et al., 2003; Pereira et al., 2003). Also, ZIKV replication causes activation of the inflammasome (Khaiboullina et al., 2017), a complex structure that is assembled upon the detection of various danger signals (Horvath et al., 2011). IL-1 $\beta$ is a gene product of the activated inflammasome (Martinon et al., 2002; Wang et al., 2002), which is a proinflammatory cytokine regulating lymphocyte differentiation (Garlanda et al., 2013). This cytokine appears to be indispensable for protection against several infectious agents (Sansonetti et al., 2000; Vonk et al., 2006; Miller et al., 2007). However, the excessive production of IL-1 $\beta$ could cause devastating consequences, damaging tissues and triggering autoimmunity (Wan et al., 2016). Increased IL-1 $\beta$ in ZIKV infected cells could be further investigated to determine its exact role in tissue damage and GBS pathogenesis.

\section{Tissue-Brain Barrier Permeability}

The integrity of the endothelial monolayer is essential for the functional capacity of the blood-tissue barrier. The barrier function is based on selective permeability, where the crossing of molecules and cells is restricted (Rodrigues and Granger, 2015). Endothelial cells act as a barrier for microbial pathogens by triggering inflammatory and coagulatory responses upon antigen recognition (Valbuena and Walker, 2006). Therefore, crossing the endothelial barrier is a crucial step for microbial dissemination and reaching the target organ. Endothelial cell death is most commonly identified as the cause of blood-tissue barrier insufficiency during viral infection (Lunardi et al., 2007; Long et al., 2013; Lin et al., 2014). Viruses target endothelium, 
which serves as the initial site of virus propagation before disseminating across the blood-tissue barrier. Flaviviruses infect and propagate in endothelial cells (Khaiboullina et al., 2005; Dalrymple and Mackow, 2011), including ZIKV (Mladinich et al., 2017; Roach and Alcendor, 2017; Peng et al., 2018). It has been suggested that ZIKV replication could affect endothelial integrity, compromising the blood-tissue barriers (Garcez et al., 2018). Therefore, the susceptibility of brain endothelial cells to ZIKV is particularly important, since virus targets the fetus neural tissue (Chan et al., 2016). By crossing fetal blood-brain barriers (BBB) and affecting blood vessel development, ZIKV could interfere with brain development and cause tissue damage. A report supporting this assumption was published by Shao et al. (2016), where abnormal density and diameter of the brain blood vessels as well as a leaky BBB were demonstrated in ZIKV infected fetus. It appears that ZIKV infection could cause embryonic endothelial cell necrosis (Szaba et al., 2018), which could help explain the fetal brain damage. Interestingly, the effect of ZIKV on endothelial cell permeability in vivo contrasts with data collected using an in vitro model (Mladinich et al., 2017). It appears that ZIKV infection does not affect brain endothelial cell monolayer permeability in vitro, although it can actively replicate and produce infectious virus (Mladinich et al., 2017). It could be suggested that the in vitro model represents an isolated system, which is limited to infection of the endothelial cells. In contrast, in vivo models include interaction between ZIKV infected endothelial cells and surrounding tissue as well as the leukocytes.

\section{Aedes Mosquito Bite Transmission}

As, ZIKV is primarily transmitted to people through the bites of infected female Aedes species mosquitoes, hence, understanding ZIKV pathogenesis relies on identification of the cellular targets of ZIKV infection, which is essential to trace virus dissemination outside of the uterus (Figure 3). Similar to other flaviviruses, the dendritic cells and endothelial cells appear to be the initial targets for ZIKV. Keratinocytes also serve as the initial site for virus replication, from which the virus spreads to endothelial cells where further virus propagation occurs. From the site of initial replication, virus disseminates via blood vessels, reaching the uterus, testicles, brain and other organs during viremia. Interestingly, ZIKV can target many immune privileged organs, such as brain, placenta and testicles, for which virus should cross blood-tissue barriers that are designed to restrict the tissue access for leukocytes and solutes. Endothelial cells are the essential structural and functional components of the BBB. Therefore, it could be suggested that by propagation in these cells, virus makes the first and the most crucial step in crossing into the tissue. Another potential mechanism for virus dissemination and crossing of the tissue barrier could be via circulating leukocytes acting as the carrier. This assumption is supported by our finding of monocytes harboring ZIKV (Khaiboullina et al., 2017). Also, monocyte susceptibility to ZIKV infection was demonstrated by Foo et al. (2017). These leukocytes were shown to be the main population carrying ZIKV in circulation (Michlmayr et al., 2017). However, many intricate details of virus trans-endothelial migration still remain unknown.

\section{Sexual Transmission}

In addition to the well characterized mosquito-borne ZIKV transmission, there are several case reports indicating that the virus can also be transmitted through sexual contact. The first case of ZIKV sexual transmission was reported in 2008 in Colorado, United States. A female patient who had not traveled to endemic areas exhibited typical symptoms of ZIKV infection. Patient reported that she had unprotected sexual intercourse with her husband, who had just returned from Senegal and was diagnosed positive for ZIKV (Foy et al., 2011). Since then, several reports indicated that ZIKV could be transmitted sexually. Most of these studies report ZIKV transmission from male-to-female partners (D'Ortenzio et al., 2016; Hills et al., 2016; McCarthy, 2016; Venturi et al., 2016), although female-tomale (Davidson et al., 2016) and male-to-male (Deckard et al., 2016) sexual transmission of ZIKV have also been reported. Notably, it has been estimated in a systematic review that male to female (92.5\%) sexual transmission of ZIKV is much more common than that of male to male $(3.7 \%)$ and female to male (3.7\%) (Moreira et al., 2017). Moreover, this study also points to the main mode of sexual transmission being the unprotected vaginal intercourse $(96.2 \%)$, followed by oral (18.5\%) and anal (7.4\%) contacts (Moreira et al., 2017). In these reported cases, sexual transmission was considered as the most likely source of infection, since ZIKV infected patients lived in Aedes mosquitoes-free regions and had unprotected sex with the partners returning from ZIKV infected areas. In most of these reported cases, transmission occurred from a patient exhibiting symptoms of ZIKV infection. However, two cases, possibly of male-to-female sexual transmission of ZIKV involving asymptomatic men, have also been reported (Brooks et al., 2016; Freour et al., 2016). These findings have very profound implications in the dynamics of ZIKV transmission, especially concerning pregnant women or those considering pregnancy. Moreover, sexual transmission could be an important factor contributing to the spread of ZIKV into new geographical areas. For instance, the Centers for Disease Control and Prevention (CDC) reported 45 cases of sexually acquired ZIKV in 2016 and seven cases in 2017 in the United States [CDC 2018 Zika Virus: 2017 Case Counts in the United States (accessed on 9 May 2018, CDC, 2018)].

Since ZIKV is present in the semen at higher levels than in urine and blood, detected by the viral RNA (Atkinson et al., 2016; Barzon et al., 2016b; D’Ortenzio et al., 2016; Mansuy et al., 2016a,b; Matheron et al., 2016; Nicastri et al., 2016), further indicated sexual transmission being the relevant route of virus transmission. It is yet not clear why ZIKV is more concentrated in semen, but it was hypothesized that virus could replicate more efficiently in the male reproductive tract (Lazear et al., 2016). The time duration for viral persistence in semen is still a matter of debate. ZIKV sexual transmission has been reported to occur 41 days following disease onset (Turmel et al., 2016). Moreover, semen of a patient returning from Haiti was positive for ZIKV RNA even 6 months after 


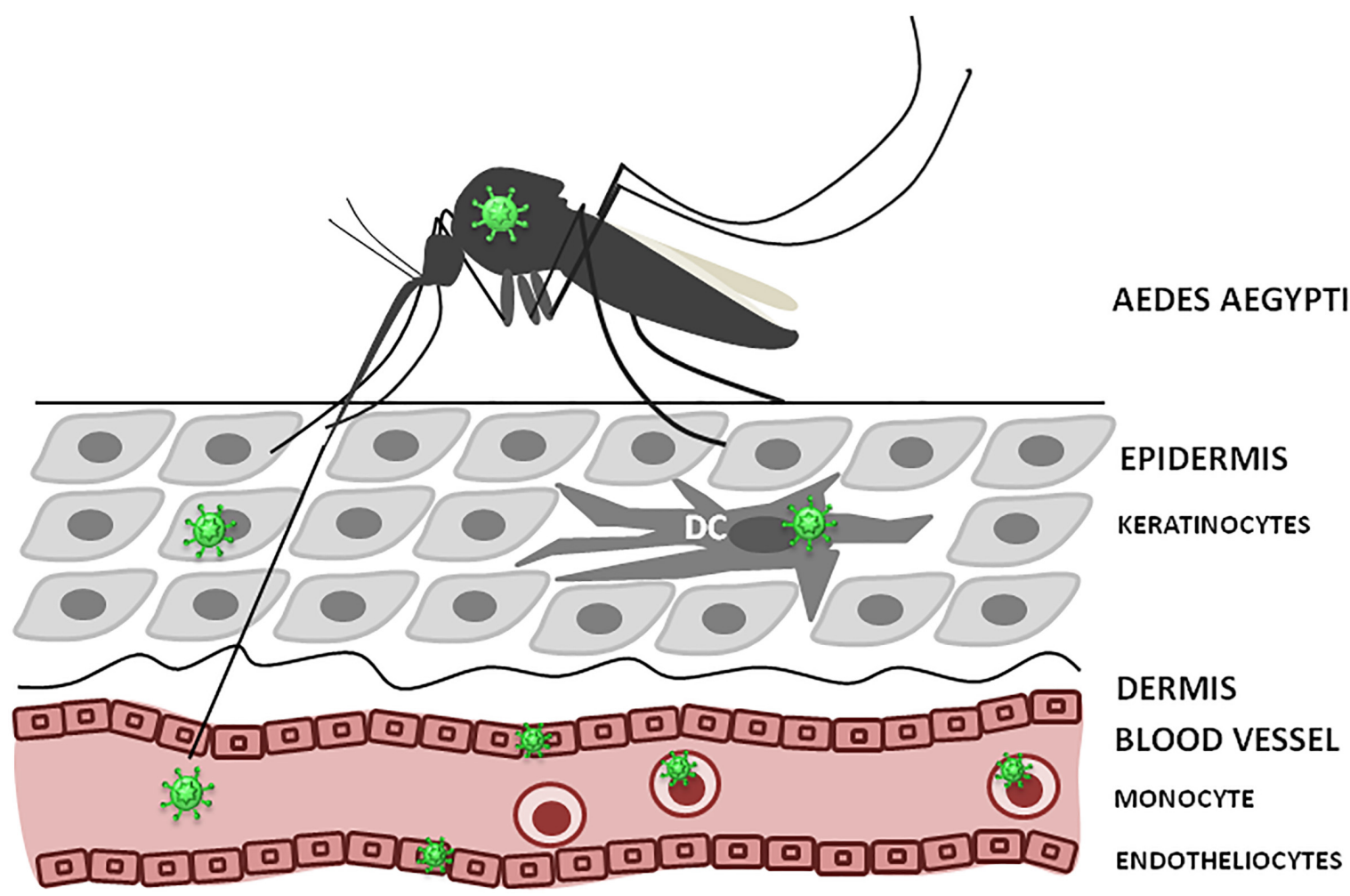

FIGURE 3 | ZIKV infection, initial replication and dissemination. ZIKV is transmitted by Aedes mosquito into theepidermis or directly into the blood. Keratinocytes, dendritic cells (DC) and endothelial cells could support virus replication at the entry site. Also, circulating monocytes could become infected and facilitate virus dissemination.

the onset of symptoms (Barzon et al., 2016b; Nicastri et al., 2016). However, infectious ZIKV could only be detected in semen up to 69 days post-infection (Arsuaga et al., 2016). In addition, a cohort study analyzing 150 patients indicates that only a small percentage of male patients showed detectable ZIKV RNA 3 months of post-infection (Paz-Bailey et al., 2017). Moreover, ZIKV RNA was detected in semen from 30 to $50 \%$ of infected men in the first month after disease onset (Musso et al., 2017a; Paz-Bailey et al., 2017). These data together suggest that sexual transmission is more likely to occur early after infection.

Regarding the female reproductive tract, ZIKV was detected in genital swab specimens from a woman's cervical mucous collected 11 days after illness onset, although urine and blood were no longer positive at this time point (Prisant et al., 2016). However, a cohort study demonstrated that only 1 out of $50 \mathrm{ZIKV}$-infected women were positive for ZIKV RNA in vaginal secretions (Paz-Bailey et al., 2017). To further understand the mechanisms underlying ZIKV infection, animal models of ZIKV intra-vaginal and sexual transmission have been developed. For instance, ZIKV was detected in rhesus macaque vaginal fluid of three non-pregnant females up to 7 days following subcutaneous inoculation (Dudley et al., 2016). Another study employing rhesus macaque indicates that both intravaginal and subcutaneous inoculation of ZIKV leads to persistent (up to 60 days post-infection) ZIKV infection in various anatomical locations, including heart, kidney, lymph nodes, and brain. Also ZIKV was detected in the vagina 8 days after intravaginal infection (Woollard et al., 2018). When female mice lacking type-I interferon (IFN) receptor were subcutaneously inoculated with ZIKV at embryonic day 6.5 or 7.5 (E6.5 or E7.5), the result was fetal demise associated with virus infection of the placenta and fetal brain (Miner et al., 2016). Moreover, wild type female mice subjected to intravaginal inoculation of ZIKV exhibited persistent viral RNA for 1-4 days post-infection, although RNA levels were no longer detected 7 days post-infection, and mice fully recovered (Yockey et al., 2016). However, type-I IFN receptor knockout mice challenged with ZIKV into the vagina demonstrated high levels of local ZIKV replication, systemic infection and death 9 days post-infection (Yockey et al., 2016). Another study, utilizing type-I IFN receptor knockout mice, has shown that males can transmit ZIKV to females through sexual contact at 3 days post-infection (Uraki et al., 2017). Moreover, it has been shown that interferon $\alpha / \beta$ and $-\gamma$ receptor knockout AG129 mice, which are both type-I and II IFN signaling incompetent, can transmit ZIKV sexually from the male to the female (Duggal et al., 2017). In fact, ZIKV infection was observed in half of the AG129 female mice mated to infected AG129 males during days 7 through 19 after inoculation (Duggal et al., 2017). Sexual transmission has also been tested in a mouse model of ZIKV, i.e., the $\operatorname{Rag} 1^{-/-}$mice 
treated with $\alpha$ IFNAR1 antibody (AIR mice), that exhibits lower levels of viral proliferation (Winkler et al., 2017a). Although disease progression was slower in this mouse model, maleto-female sexual transmission was observed when type-I IFN receptor knockout females were mated with infected AIR males 8-12 days post-infection (Winkler et al., 2017b). Moreover, sexual transmission of ZIKV in this model led to infection of the uterus and placenta of mice that became pregnant, although fetuses were spared (Winkler et al., 2017b). It is still unclear what factors could protect females from ZIKV intravaginal infection. However, it was shown that progesterone levels appear to impact intravaginal infection, since administration of ZIKV into the vagina of AG129 mice triggers viral systemic infection and death when infection takes place in the diestrus-like phase, although estrus-like mice are resistant to ZIKV intravaginal infection (Tang et al., 2016). Moreover, administration of Depoprovera (medroxyprogesterone) to rhesus macaques allows preferential replication of ZIKV in the female reproductive tract following intravaginal transmission, but not after subcutaneous transmission (Carroll et al., 2017).

\section{Secondary Modes of Transmission}

Zika virus could be detected in several body fluids including blood, breast milk, saliva, urine, sweat and tears (Calvet et al., 2018). Therefore, a secondary mode of ZIKV transmission was suggested, in which virus could be passed during the blood transfusion or breast feeding.

\section{Blood}

Blood samples are reported to be consistently positive for $\mathrm{ZIKV}$, although viremia is transient and virus titer is lower than in urine or sperm (Lanciotti et al., 2008). Up to $28.1 \%$ of patients were reported to have a viremia (Musso et al., 2017b), where 3\% were shown clinically asymptomatic (Musso et al., 2017b). Since the majority of ZIKV infected cases are asymptomatic, the risk of infection via blood transfusion remains high. It became an important public safety concern when ZIKV transmission via blood transfusion was reported by Barjas-Castro et al. (2016). The alarming news of ZIKV infection via blood transfusion prompted the US Food and Drug administration to recommend blood donor and blood product screening to reduce the risk of infection (Center for Biologics Evaluation and Research, 2018).

\section{Breast Milk}

Breastfeeding was suggested as a mode of ZIKV infection in three clinical cases (Colt et al., 2017). In all three cases, ZIKV was detected in the breast milk by RT-PCR. ZIKV infection was confirmed in two breastfed newborns, where symptoms were limited to maculopapular rash without adverse effects on the brain growth or function. In a comprehensive systemic review, Colt et al. (2017) conclude that the data on breast milk transmission of ZIKV is insufficient and render more clinical data collection for the analysis. Although ZIKV transmission via breast milk was suggested in 2 cases, breastfeeding is still considered to be safe for the newborns. Therefore, WHO does not impose restrictions on the breastfeeding guidelines and recommends initiating breastfeeding within 1 hour of delivery (WHO, 2018).

\section{Saliva}

Saliva appears to be the excellent source for ZIKV detection where $57.1 \%$ samples were found positive for virus antigen (Musso et al., 2015). Interestingly, ZIKV detection in saliva was twice that in the blood $(28.1 \%)$, suggesting that salivary glands are the sites of ZIKV replication. These data suggest that saliva could be the source of ZIKV transmission, especially in the endemic areas. Additionally, saliva transmission could play a role in sporadic outbreaks in non-endemic areas. Barzon et al. (2016a) reported detection of ZIKV in saliva of an Italian traveler returning from Dominican Republic. ZIKV was detected in saliva samples up to 29 days after the disease onset and it remained detectible longer than in blood. Therefore, ZIKV in saliva could contribute to the local epidemic as well as outbreaks in non-endemic areas.

\section{Sweat and Tears}

Zika virus can cause conjunctivitis and uveitis in up to $15 \%$ of infected adults (Furtado et al., 2016; Petersen et al., 2016), suggesting that eyes could be a site of virus replication. ZIKV was detected in conjunctival swabs from $10 \%$ of convalescent patients 30 days after the recovery. Although viral copies were low (5.2 to 9.3 copies per swab), detection of the virus in tear samples late after the recovery suggests that virus could establish long-term replication in selected sites. Interestingly, presumptive tears or sweat as a source of infection was suggested in a ZIKV case published by Swaminathan et al. (2016). Although this is the single study where tear/sweat source of infection was suggested, the data presents these sources as plausible and playing a role in the ZIKV epidemic.

\section{Urine}

Zika virus is consistently demonstrated in all urine samples studied by Gourinat et al. (2015). ZIKV nucleic acid was detected for up to 20 days after the onset of symptoms, which was longer than that in blood samples. Even longer, 21 days after the onset of neurological symptoms, virus shedding was demonstrated in patients diagnosed with GBS (Roze et al., 2016). The late detection of ZIKV RNA in the urine was reported by Campos Rde et al. (2016), suggesting that virus could be replicating in kidney tissue. This assumption is supported by the fact that ZIKV RNA could be found in urine long after the virus has being cleared from the circulation and no longer detected in the blood (Gourinat et al., 2015). ZIKV in the urine remains infectious, as several isolates from urine samples were established. The first ZIKV isolate was described in 2014 by Fonseca et al. (2014). Later, more ZIKV isolates were characterized (Bonaldo et al., 2016), including a travel-associated ZIKV, reported by Barzon et al. (2016a). Although infectious virus is readily detected in the urine, there is no documented case of urine exposure linked ZIKV infection. Nevertheless, urine samples should be 
considered as a potential source of infection and treated as biohazard material.

\section{Risk of Congenital Transmission Due to Intravaginal ZIKV Infection}

Congenital ZIKV infection can cause microcephaly and severe brain abnormalities (de Araujo et al., 2016; SchulerFaccini et al., 2016). The Congenital Zika Syndrome (CZS), i.e., neuropathological conditions that emerge after ZIKV intrauterine transmission, is characterized by severe microcephaly, a partially collapsed skull, decreased brain tissue with a specific pattern of brain damage and calcifications, eye alterations, congenital contractures, and hypertonia restricting body movements (Moore et al., 2017). However, not all pregnant women infected with ZIKV give birth to babies with CZS. For instance, among 117 babies born from symptomatic ZIKVpositive mothers in Rio de Janeiro, 49 (42\%) presented with abnormal clinical and/or brain imaging findings, including 4 infants with microcephaly (Brasil et al., 2016). Another report by Reynolds et al. (2017) analyzed 972 fetuses/infants from completed pregnancies with laboratory evidence of possible ZIKV infection and identified 51 fetuses/infants (5\%) exhibiting ZIKV-related birth defects. However, when only laboratoryconfirmed ZIKV cases were studied, a higher proportion of fetuses/infants (24 out of $250,10 \%$ ) was found to have ZIKVrelated birth defects (Reynolds et al., 2017). When ZIKV infection occurred in the first trimester of pregnancy, birth defects were reported in 15\% of fetuses/infants (Reynolds et al., 2017). Moreover, another study estimated the risk of microcephaly due to ZIKV infection between 0.88 and $13.2 \%$ in cases of viral infection in the first trimester of pregnancy (Johansson et al., 2016). Compared to the prevalence during pre-ZIKV years, the proportion of fetuses/infants displaying birth defects among pregnancies with confirmed ZIKV infection was 30 times higher when infection took place at any time during pregnancy and even higher when infection occurred in the first trimester (Cragan et al., 2017). Moreover, it appears that birth defects occur regardless of whether infections during the pregnancy are symptomatic or asymptomatic (Cragan et al., 2017). Thus, these findings suggest that all pregnant women should be screened for possible ZIKV exposure to facilitate appropriate intervention.

As only a fraction of infected pregnant women give birth to babies with birth defects, it is possible that additional factors might contribute to ZIKV-triggered neurological alterations. Several factors have been suggested to play a role in ZIKVrelated birth defects, including poor living conditions (Souza et al., 2018). For instance, from November 2015 to February 2016 , out of the 1,501 livebirths registered with microcephaly, approximately $90 \%$ were born in the Northeast of Brazil, a region that faces many socio-economic problems and poor nutrition (Franca et al., 2016). In Recife (Pernambuco, Brazil), a city that was severely affected by ZIKV congenital malformations, the majority of the microcephaly cases in 2015 and 2016 were reported in areas with very impoverished living conditions (Nem de Oliveira Souza et al., 2018). However, there are many factors that complicate the interpretation of the correlation between poor living conditions and the prevalence of CZS. For example, deprived areas are overcrowded and lack basic sanitation, providing an ideal environment for transmission of vector-borne diseases (Braga et al., 2010). Thus, it is possible that CZS could be more common in these areas because of the high prevalence of ZIKV infection itself.

Although it is very hard to measure sexual transmission in endemic areas, epidemiological studies have reported increased incidence of ZIKV infections in pregnant women during the outbreaks (Duffy et al., 2009; Coelho et al., 2016), which could be due to male-to-female sexual transmission. It is still unknown if sexual transmission poses a different and higher risk to congenital infection than mosquito-borne transmission. Several studies have demonstrated that ZIKV replicates in the vaginal tract, and sexual transmission during the early phase of pregnancy can lead to birth defects in mice (Yockey et al., 2016; Duggal et al., 2017; Uraki et al., 2017; Winkler et al., 2017b). For instance, it was shown that vaginal infection of pregnant mice can trigger ZIKV infection of the fetus and promote brain developmental abnormalities (Yockey et al., 2016). When wild type dams were infected with ZIKV into the vagina embryos exhibited growth defects, although viral RNA could not be detected in the placenta and fetal body (Yockey et al., 2016). However, when type-I IFN knockout dams were subjected to intravaginal infection, higher levels of ZIKV RNA were observed in the placenta and fetal body (Yockey et al., 2016). Infection of type-I IFN knockout dams with ZIKV was more deleterious when it was done at E4.5, as all fetuses were reabsorbed, whereas when infection took place at E8.5, fetuses survived but developed reduced body weight (Yockey et al., 2016). Moreover, sexual transmission of ZIKV between infected male and female mice that lack type-I IFN receptors resulted in restricted growth and ocular malformations in fetuses (Uraki et al., 2017). These data highlight the importance of the innate immune response in controlling ZIKV proliferation following intravaginal infection. In addition, these results also demonstrate that intravaginal infection is a potential route for fetus infection, especially in the first trimester of pregnancy.

It is still unclear whether sexual transmission could facilitate ZIKV spread in the vagina and uterus and what factors could contribute to this infection. Notably, a recently published study indicates that sexual transmission promotes significantly greater morbidity and mortality of AG129 female mice as well as higher ZIKV titers in the female reproductive tract as compared to sub-cutaneous and intravaginal infection (Duggal et al., 2018). Moreover, the percentage of ZIKV positive fetuses was higher when females were infected sexually (88\%), as compared to sub- cutaneous $(50 \%)$ or intravaginal (53\%) inoculation routes (Duggal et al., 2018). These data suggest that sexual transmission could account for some of the fetal alterations observed even within Aedes endemic regions. Further studies will be determine whether an ascending infection from the vagina to the fetus provides an easier path for fetal infection than a mosquito bite, or whether the two events combined would facilitate the development of CZS. 


\section{CONCLUSION}

The 2015 ZIKV outbreak caused an alarming situation linking the mosquito-borne flavivirus to devastating birth defects, such as microcephaly (unusually smaller-than normal size of the head). ZIKV seems to be the first flavivirus with the unique ability to traverse, infect and damage the placenta, which is resistant to most pathogens, as traces of the virus have been confirmed in the central nervous system and amniotic fluid of the affected babies. Although, many promising findings begin to uncover the complex role of the placenta in the pathobiology of ZIKV infection, several important events linking ZIKV infection to mammalian brain growth deficits still remain poorly characterized. Evidently, more extensive and long-term studies unraveling the major complications of fetal injury and death in utero are warranted. Considering the significant role in ZIKV-related fetal abnormalities, understanding placentainduced vertical transmission and fetal brain injury would be valuable. Some of the challenges involved in studying placental infection and damage in model systems include isolation of placental primary cells/trophoblasts, morphological differences between murine and human placentas, and distinct placental inflammatory responses among mammals. In addition, most models of ZIKV infection during human pregnancy investigate the second or the third trimester placentae that differs both, in structure and cellular composition, from the first trimester placentae, which is the period mainly associated with intrauterine growth restrictions, severe microcephaly and ocular abnormalities.

Coordinated interdisciplinary studies are needed to understand the sudden emergence and asymmetric geographic distribution of CZS among ZIKV infection cases. Studies

\section{REFERENCES}

Adibi, J. J., Marques, E. T. Jr., Cartus, A., and Beigi, R. H. (2016). Teratogenic effects of the Zika virus and the role of the placenta. Lancet 387, 1587-1590. doi: 10.1016/S0140-6736(16)00650-4

Alimonti, J. B., Ribecco-Lutkiewicz, M., Sodja, C., Jezierski, A., Stanimirovic, D. B., Liu, Q., et al. (2018). Zika virus crosses an in vitro human blood brain barrier model. Fluids Barriers CNS 15:15. doi: 10.1186/s12987-018-0100-y

Arias, R. A., Muñoz, L. D., and Muñoz-Fernández, M. A. (2003). Transmission of HIV-1 infection between trophoblast placental cells and T-cells take place via an LFA-1-mediated cell to cell contact. Virology 307, 266-277. doi: 10.1016/s00426822(02)00040-5

Arsuaga, M., Bujalance, S. G., Díaz-Menéndez, M., Vázquez, A., and Arribas, J. R. (2016). Probable sexual transmission of Zika virus from a vasectomised man. Lancet Infect. Dis. 16:1107. doi: 10.1016/s1473-3099(16)30320-6

Atkinson, B., Hearn, P., Afrough, B., Lumley, S., Carter, D., Aarons, E. J., et al. (2016). Detection of Zika Virus in Semen. Emerg. Infect. Dis 22:940.

Barjas-Castro, M. L., Angerami, R. N., Cunha, M. S., Suzuki, A., Nogueira, J. S., Rocco, I. M., et al. (2016). Probable transfusion-transmitted Zika virus in Brazil. Transfusion 56, 1684-1688. doi: 10.1111/trf.13681

Barzon, L., Pacenti, M., Berto, A., Sinigaglia, A., Franchin, E., Lavezzo, E., et al. (2016a). Isolation of infectious Zika virus from saliva and prolonged viral RNA shedding in a traveller returning from the Dominican Republic to Italy, January 2016. Euro. Surveill. 21:30159. doi: 10.2807/1560-7917.ES.2016.21.10.30159

Barzon, L., Pacenti, M., Franchin, E., Lavezzo, E., Trevisan, M., Sgarabotto, D., et al. (2016b). Infection dynamics in a traveller with persistent shedding of Zika virus deciphering the impact of ZIKV transmission and CZS prevalence are often confounded by underestimation of ZIKV infected individuals, poor differential diagnosis between microcephaly and intrauterine growth restriction, and immunological cross-reactivity among flaviviruses. Whether infants exposed to ZIKV infection postnatally will experience any prolonged negative outcomes is still unknown, so the close long-term surveillance and treatment of potentially affected infants and their families will be necessary.

\section{AUTHOR CONTRIBUTIONS}

SFK wrote the sections "Introduction", "Epidemiology", part of "Modes of Transmission" and "Conclusion." FMR wrote parts of the section "Modes of Transmission." TU wrote the section "Genomic Structure." EVM created the figures. AAR made intellectual contribution into the discussion. SCV contributed to overall supervision of the review process, editing of the manuscript, and managing several research teams.

\section{FUNDING}

This work was supported by Institutional and Departmental Funds. SFK, EVM, and AAR were supported by the Program of Competitive Growth of Kazan Federal University. This work was partly supported by a grant from the National Institute of General Medical Sciences (GM103440) from the National Institutes of Health.

RNA in semen for six months after returning from Haiti to Italy, January 2016. Euro. Surveill. 21:30316. doi: 10.2807/1560-7917.ES.2016.21.32.30316

Baud, D., Gubler, D. J., Schaub, B., Lanteri, M. C., and Musso, D. (2017). An update on Zika virus infection. Lancet 390, 2099-2109. doi: 10.1016/S0140-6736(17) 31450-2

Bonaldo, M. C., Ribeiro, I. P., Lima, N. S., Dos Santos, A. A., Menezes, L. S., da Cruz, S. O., et al. (2016). Isolation of infective Zika Virus from urine and saliva of patients in Brazil. PLoS Negl. Trop. Dis. 10:e0004816. doi: 10.1371/journal. pntd.0004816

Bowen, J. R., Quicke, K. M., Maddur, M. S., O’Neal, J. T., McDonald, C. E., Fedorova, N. B., et al. (2017). Zika virus antagonizes type I interferon responses during infection of human dendritic cells. PLoS Pathog. 13:e1006164. doi: 10. 1371/journal.ppat.1006164

Braga, C., Luna, C. F., Martelli, C. M., de Souza, W. V., Cordeiro, M. T., Alexander, N., et al. (2010). Seroprevalence and risk factors for dengue infection in socioeconomically distinct areas of Recife, Brazil. Acta Trop. 113, 234-240. doi: 10.1016/j.actatropica.2009.10.021

Brasil, P., Pereira, J. P. Jr., Moreira, M. E., Ribeiro Nogueira, R. M., Damasceno, L., et al. (2016). Zika virus infection in pregnant women in Rio de Janeiro. N. Engl. J. Med. 375, 2321-2334.

Brooks, R. B., Carlos, M. P., Myers, R. A., White, M. G., Bobo-Lenoci, T., Aplan, D., et al. (2016). Likely sexual transmission of Zika Virus from a man with no symptoms of infection - Maryland, 2016. MMWR Morb. Mortal. Wkly. Rep. 65, 915-916. doi: 10.15585/mmwr.mm6534e2

Brown, J. A., Singh, G., Acklin, J. A., Lee, S., Duehr, J. E., Chokola, A. N., et al. (2019). Dengue virus immunity increases zika virus-induced damage 
during pregnancy. Immunity 50, 751.e5-762.e5. doi: 10.1016/j.immuni.2019.0 1.005

Calvet, G. A., Kara, E. O., Giozza, S. P., Bôtto-Menezes, C. H. A., Gaillard, P., de Oliveira Franca, R. F., et al. (2018). Study on the persistence of Zika virus (ZIKV) in body fluids of patients with ZIKV infection in Brazil. BMC Infect. Dis. 18:49. doi: 10.1186/s12879-0182965-4

Calvet, G. A., Santos, F. B., and Sequeira, P. C. (2016). Zika virus infection: epidemiology, clinical manifestations and diagnosis. Curr. Opin. Infect. Dis. 29, 459-466. doi: 10.1097/qco.0000000000000301

Campos Rde, M., Cirne-Santos, C., Meira, G. L., Santos, L. L., de Meneses, M. D., Friedrich, J., et al. (2016). Prolonged detection of Zika virus RNA in urine samples during the ongoing Zika virus epidemic in Brazil. J. Clin. Virol. 77, 69-70. doi: 10.1016/j.jcv.2016.02.009

Cao-Lormeau, V. M., Blake, A., Mons, S., Lastere, S., Roche, C., Vanhomwegen, J., et al. (2016). Guillain-Barre Syndrome outbreak associated with Zika virus infection in French polynesia: a case-control study. Lancet 387, 1531-1539. doi: 10.1016/S0140-6736(16)00562-6

Cao-Lormeau, V. M., Roche, C., Teissier, A., Robin, E., Berry, A. L., Mallet, H. P., et al. (2014). Zika virus, French polynesia, South pacific, 2013. Emerg. Infect. Dis. 20, 1085-1086.

Carroll, T., Lo, M., Lanteri, M., Dutra, J., Zarbock, K., Silveira, P., et al. (2017). Zika virus preferentially replicates in the female reproductive tract after vaginal inoculation of rhesus macaques. PLoS Pathog. 13:e1006537. doi: 10.1371/ journal.ppat.1006537

Carvalho, R. G., Lourenco-de-Oliveira, R., and Braga, I. A. (2014). Updating the geographical distribution and frequency of Aedes albopictus in Brazil with remarks regarding its range in the Americas. Mem. Inst. Oswaldo Cruz 109, 787-796. doi: 10.1590/0074-0276140304

Cauchemez, S., Besnard, M., Bompard, P., Dub, T., Guillemette-Artur, P., EyrolleGuignot, D., et al. (2016). Association between Zika virus and microcephaly in French Polynesia, 2013-15: a retrospective study. Lancet 387, 2125-2132. doi: 10.1016/S0140-6736(16)00651-6

CDC (2016). 2016 Case Counts in the US. Atlanta, GA: CDC.

CDC (2017). About 1 in 10 U.S. Pregnant Women with Confirmed Zika Infection had a Fetus or Baby with Birth Defects in 2016. Atlanta, GA: CDC.

CDC (2018). 2017 Case Counts in the US. Atlanta, GA: CDC.

Center for Biologics Evaluation and Research (2018). Revised Recommendations for Reducing the Risk of Zika Virus Transmission by Blood and Blood Components. Guidance for Industry. Maryland, MD: Center for Biologics Evaluation and Research.

Chan, J. F., Yip, C. C., Tsang, J. O., Tee, K. M., Cai, J. P., Chik, K. K., et al. (2016). Differential cell line susceptibility to the emerging Zika virus: implications for disease pathogenesis, non-vector-borne human transmission and animal reservoirs. Emerg. Microbes Infect. 5: e93. doi: 10.1038/emi.2016.99

Coelho, F. C., Durovni, B., Saraceni, V., Lemos, C., Codeco, C. T., Camargo, S., et al. (2016). Higher incidence of Zika in adult women than adult men in Rio de Janeiro suggests a significant contribution of sexual transmission from men to women. Int. J. Infect. Dis. 51, 128-132. doi: 10.1016/j.ijid.2016.08.023

Colt, S., Garcia-Casal, M. N., Peña-Rosas, J. P., Finkelstein, J. L., Rayco-Solon, P., Weise Prinzo, Z. C., et al. (2017). Transmission of Zika virus through breast milk and other breastfeeding-related bodily-fluids: a systematic review. PLoS Negl. Trop. Dis. 11:e0005528. doi: 10.1371/journal.pntd.0005528

Cragan, J. D., Mai, C. T., Petersen, E. E., Liberman, R. F., Forestieri, N. E., Stevens, A. C., et al. (2017). Baseline prevalence of birth defects associated with congenital zika virus infection - Massachusetts, North Carolina, and Atlanta, Georgia, 2013-2014. MMWR Morb. Mortal. Wkly. Rep. 66, 219-222. doi: 10. 15585/mmwr.mm6608a4

Dalrymple, N., and Mackow, E. R. (2011). Productive dengue virus infection of human endothelial cells is directed by heparan sulfate-containing proteoglycan receptors. J. Virol. 85, 9478-9485. doi: 10.1128/JVI.05008-11

Davidson, A., Slavinski, S., Komoto, K., Rakeman, J., and Weiss, D. (2016). Suspected female-to-male sexual transmission of zika virus - New York City, 2016. MMWR Morb. Mortal. Wkly. Rep. 65, 716-717. doi: 10.15585/mmwr. mm6528e2

de Araujo, T. V. B., Rodrigues, L. C., de Alencar Ximenes, R. A., de Barros MirandaFilho, D., Montarroyos, U. R., de Melo, A. P. L., et al. (2016). Association between Zika virus infection and microcephaly in Brazil, January to May, 2016: preliminary report of a case-control study. Lancet Infect. Dis. 16, 1356-1363. doi: 10.1016/S1473-3099(16)30318-8

de Oliveira, W. K., de Franca, G. V. A., Carmo, E. H., Duncan, B. B., de Souza Kuchenbecker, R., and Schmidt, M. I. (2017). Infection-related microcephaly after the 2015 and 2016 Zika virus outbreaks in Brazil: a surveillance-based analysis. Lancet 390, 861-870. doi: 10.1016/S0140-6736(17)31368-5

Deckard, D. T., Chung, W. M., Brooks, J. T., Smith, J. C., Woldai, S., Hennessey, M., et al. (2016). Male-to-male sexual transmission of Zika Virus- Texas, January 2016. MMWR Morb. Mortal. Wkly. Rep. 65, 372-374. doi: 10.15585/mmwr. mm6514a3

Devhare, P., Meyer, K., Steele, R., Ray, R. B., and Ray, R. (2017). Zika virus infection dysregulates human neural stem cell growth and inhibits differentiation into neuroprogenitor cells. Cell Death Dis 8, e3106. doi: 10.1038/cddis.2017.517

Dick, G. W. (1952). Zika virus. II. Pathogenicity and physical properties. Trans. $R$. Soc. Trop. Med. Hyg. 46, 521-534. doi: 10.1016/0035-9203(52)90043-6

Dick, G. W., Kitchen, S. F., and Haddow, A. J. (1952). Zika virus. I. Isolations and serological specificity. Trans. R. Soc. Trop. Med. Hyg. 46, 509-520. doi: 10.1016/0035-9203(52)90042-4

Dong, H., Chang, D. C., Hua, M. H., Lim, S. P., Chionh, Y. H., Hia, F., et al. (2012). 2'-O methylation of internal adenosine by flavivirus NS5 methyltransferase. PLoS Pathog. 8:e1002642. doi: 10.1371/journal.ppat.1002642

Dong, S., and Liang, Q. (2018). Recent advances in animal models of zika virus infection. Virol. Sin. 33, 125-130. doi: 10.1007/s12250-018-0007-4

D’Ortenzio, E., Matheron, S., Yazdanpanah, Y., de Lamballerie, X., Hubert, B., Piorkowski, G., et al. (2016). Evidence of sexual transmission of zika virus. N. Engl. J. Med. 374, 2195-2198.

Dudley, D. M., Aliota, M. T., Mohr, E. L., Weiler, A. M., Lehrer-Brey, G., Weisgrau, K. L., et al. (2016). A rhesus macaque model of Asian-lineage Zika virus infection. Nat. Commun. 7:12204. doi: 10.1038/ncomms12204

Duffy, M. R., Chen, T. H., Hancock, W. T., Powers, A. M., Kool, J. L., Lanciotti, R. S., et al. (2009). Zika virus outbreak on Yap Island, Federated States of Micronesia. N. Engl. J. Med. 360, 2536-2543. doi: 10.1056/NEJMoa0805715

Duggal, N. K., McDonald, E. M., Ritter, J. M., and Brault, A. C. (2018). Sexual transmission of Zika virus enhances in utero transmission in a mouse model. Sci. Rep. 8:4510. doi: 10.1038/s41598-018-22840-6

Duggal, N. K., Ritter, J. M., Pestorius, S. E., Zaki, S. R., Davis, B. S., Chang, G. J., et al. (2017). Frequent zika virus sexual transmission and prolonged viral RNA Shedding in an immunodeficient mouse model. Cell Rep. 18, 1751-1760. doi: 10.1016/j.celrep.2017.01.056

Egloff, M. P., Benarroch, D., Selisko, B., Romette, J. L., and Canard, B. (2002). An RNA cap (nucleoside-2'-O-)-methyltransferase in the flavivirus RNA polymerase NS5: crystal structure and functional characterization. EMBO J. 21, 2757-2768. doi: 10.1093/emboj/21.11.2757

El Costa, H., Gouilly, J., Mansuy, J. M., Chen, Q., Levy, C., Cartron, G., et al. (2016). ZIKA virus reveals broad tissue and cell tropism during the first trimester of pregnancy. Sci. Rep. 6, 35296. doi: 10.1038/srep35296

European Centre for Disease Prevention, and Control (2016). Rapid Risk Assessment: Zika Virus Disease Epidemic: Potential Association with Microcephaly and Guillain-Barré syndrome. Solna: European Centre for Disease Prevention, and Control.

Fonseca, K., Meatherall, B., Zarra, D., Drebot, M., MacDonald, J., Pabbaraju, K., et al. (2014). First case of Zika virus infection in a returning Canadian traveler. Am. J. Trop. Med. Hyg. 91, 1035-1038. doi: 10.4269/ajtmh.14-0151

Foo, S. S., Chen, W., Chan, Y., Bowman, J. W., Chang, L. C., Choi, Y., et al. (2017). Asian Zika virus strains target CD14(+) blood monocytes and induce M2skewed immunosuppression during pregnancy. Nat. Microbiol. 2, 1558-1570. doi: 10.1038/s41564-017-0016-3

Foy, B. D., Kobylinski, K. C., Chilson Foy, J. L., Blitvich, B. J., Travassos da Rosa, A., Haddow, A. D., et al. (2011). Probable non-vector-borne transmission of Zika virus, Colorado, USA. Emerg. Infect. Dis. 17, 880-882. doi: 10.3201/eid1705. 101939

Franca, G. V. A., Pedi, V. D., Garcia, M. H. O., Carmo, G. M. I. D., Leal, M. B., and Garcia, L. P. (2018). Congenital syndrome associated with Zika virus infection among live births in Brazil: a description of the distribution of reported and confirmed cases in 2015-2016. Epidemiol. Serv. Saude 27:e2017473. doi: 10. 5123/S1679-49742018000200014

Franca, G. V., Schuler-Faccini, L., Oliveira, W. K., Henriques, C. M., Carmo, E. H., Pedi, V. D., et al. (2016). Congenital Zika virus syndrome in Brazil: a case series 
of the first 1501 livebirths with complete investigation. Lancet 388, 891-897. doi: 10.1016/S0140-6736(16)30902-3

Freour, T., Mirallie, S., Hubert, B., Splingart, C., Barrière, P., Maquart, M., et al. (2016). Sexual transmission of Zika virus in an entirely asymptomatic couple returning from a Zika epidemic area, France, April 2016. Euro. Surveill. 21:30254. doi: 10.2807/1560-7917.ES.2016.21.23.30254

Furtado, J. M., Esposito, D. L., Klein, T. M., Teixeira-Pinto, T., and da Fonseca, B. A. (2016). Uveitis Associated with Zika Virus Infection. N. Engl. J. Med. 375, 394-396.

Garcez, P. P., Stolp, H. B., Sravanam, S., Christoff, R. R., Ferreira, J. C. C. G., Dias, A. A., et al. (2018). Zika virus impairs the development of blood vessels in a mouse model of congenital infection. Sci. Rep. 8:12774. doi: 10.1038/s41598018-31149-3

Garlanda, C., Dinarello, C. A., and Mantovani, A. (2013). The interleukin-1 family: back to the future. Immunity 39, 1003-1018. doi: 10.1016/j.immuni.2013.11. 010

Gong, Z., Gao, Y., and Han, G. Z. (2016). Zika virus: two or three lineages?. Trends Microbiol. 24, 521-522. doi: 10.1016/j.tim.2016.05.002

Gourinat, A. C., O'Connor, O., Calvez, E., Goarant, C., and Dupont-Rouzeyrol, M. (2015). Detection of Zika virus in urine. Emerg. Infect. Dis. 21, 84-86. doi: $10.3201 /$ eid2101.140894

Grifoni, A., Pham, J., Sidney, J., O'Rourke, P. H., Paul, S., Peters, B., et al. (2017). Prior Dengue virus exposure shapes $\mathrm{T}$ cell immunity to Zika virus in humans. J. Virol. 91:e01469-17. doi: 10.1128/JVI.01469-17

Guzman, M. G., Kouri, G., Martínez, E., Bravo, J., Riverón, R., Soler, M., et al. (1987). Clinical and serologic study of Cuban children with dengue hemorrhagic fever/dengue shock syndrome (DHF/DSS). Bull. Pan Am. Health Organ. 21, 270-279.

Haddow, A. D., Schuh, A. J., Yasuda, C. Y., Kasper, M. R., Heang, V., Huy, R., et al. (2012). Genetic characterization of Zika virus strains: geographic expansion of the Asian lineage. PLoS Negl. Trop. Dis. 6:e1477. doi: 10.1371/journal.pntd. 0001477

Hamel, R., Dejarnac, O., Wichit, S., Ekchariyawat, P., Neyret, A., Luplertlop, N., et al. (2015). Biology of zika virus infection in human skin cells. J. Virol. 89, 8880-8896. doi: 10.1128/JVI.00354-15

Hasan, S. S., Sevvana, M., Kuhn, R. J., and Rossmann, M. G. (2018). Structural biology of Zika virus and other flaviviruses. Nat. Struct. Mol. Biol. 25, 13-20. doi: 10.1038/s41594-017-0010-8

Hastings, A. K., Yockey, L. J., Jagger, B. W., Hwang, J., Uraki, R., Gaitsch, H. F., et al. (2017). TAM receptors are not required for zika virus infection in mice. Cell Rep. 19, 558-568. doi: 10.1016/j.celrep.2017.03.058

Heukelbach, J., Alencar, C. H., Kelvin, A. A., de Oliveira, W. K., and Pamplona de Góes Cavalcanti, L. (2016). Zika virus outbreak in Brazil. J. Infect. Dev. Ctries $10,116-120$

Hills, S. L., Russell, K., Hennessey, M., Williams, C., Oster, A. M., Fischer, M., et al. (2016). Transmission of zika virus through sexual contact with travelers to areas of ongoing transmission - Continental United States, 2016. MMWR Morb. Mortal. Wkly. Rep. 65, 215-216. doi: 10.15585/mmwr.mm6508e2

Himmelsbach, K., and Hildt, E. (2018). Identification of various cell culture models for the study of Zika virus. World J. Virol. 7, 10-20. doi: 10.5501/wjv.v7.i1.10

Horvath, G. L., Schrum, J. E., De Nardo, C. M., and Latz, E. (2011). Intracellular sensing of microbes and danger signals by the inflammasomes. Immunol. Rev. 243, 119-135. doi: 10.1111/j.1600-065X.2011.01050.x

Johansson, M. A., Mier-y-Teran-Romero, L., Reefhuis, J., Gilboa, S. M., and Hills, S. L. (2016). Zika and the risk of microcephaly. N. Engl. J. Med. 375, 1-4.

Khaiboullina, S. F., Rizvanov, A. A., Holbrook, M. R., and St Jeor, S. (2005). Yellow fever virus strains Asibi and 17D-204 infect human umbilical cord endothelial cells and induce novel changes in gene expression. Virology 342, 167-176. doi: $10.1016 /$ j.virol.2005.07.035

Khaiboullina, S. F., Uppal, T., Sarkar, R., Gorzalski, A., St Jeor, S., and Verma, S. C. (2017). ZIKV infection regulates inflammasomes pathway for replication in monocytes. Sci. Rep. 7:16050. doi: 10.1038/s41598-017-16072-3

Kostyuchenko, V. A., Lim, E. X., Zhang, S., Fibriansah, G., Ng, T. S., Ooi, J. S., et al. (2016). Structure of the thermally stable Zika virus. Nature 533, 425-428. doi: 10.1038/nature17994

Kraemer, M. U., Sinka, M. E., Duda, K. A., Mylne, A. Q., Shearer, F. M., Barker, C. M., et al. (2015). The global distribution of the arbovirus vectors Aedes aegypti and Ae. albopictus. eLife 4:e08347. doi: 10.7554/eLife.08347
Lanciotti, R. S., Kosoy, O. L., Laven, J. J., Velez, J. O., Lambert, A. J., Johnson, A. J., et al. (2008). Genetic and serologic properties of Zika virus associated with an epidemic, Yap State, Micronesia, 2007. Emerg. Infect. Dis. 14, 1232-1239. doi: $10.3201 /$ eid1408.080287

Lazear, H. M., Govero, J., Smith, A. M., Platt, D. J., Fernandez, E., Miner, J. J., et al. (2016). A mouse model of zika virus pathogenesis. Cell Host Microbe 19, 720-730. doi: 10.1016/j.chom.2016.03.010

Leung, J. Y., Pijlman, G. P., Kondratieva, N., Hyde, J., Mackenzie, J. M., and Khromykh, A. A. (2008). Role of nonstructural protein NS2A in flavivirus assembly. J. Virol. 82, 4731-4741. doi: 10.1128/JVI.00002-08

Li, H., Clum, S., You, S., Ebner, K. E., and Padmanabhan, R. (1999). The serine protease and RNA-stimulated nucleoside triphosphatase and RNA helicase functional domains of dengue virus type 2 NS3 converge within a region of 20 amino acids. J. Virol. 73, 3108-3116.

Liang, Q., Luo, Z., Zeng, J., Chen, W., Foo, S. S., Lee, S. A., et al. (2016). Zika Virus NS4A and NS4B proteins deregulate Akt-mTOR signaling in human fetal neural stem cells to inhibit neurogenesis and induce autophagy. Cell Stem Cell 19, 663-671. doi: 10.1016/j.stem.2016.07.019

Lim, S. K., Lim, J. K., and Yoon, I. (2017). An update on zika virus in Asia. Infect. Chemother. 49, 91-100.

Lin, J. C., Lin, S. C., Chen, W. Y., Yen, Y. T., Lai, C. W., Tao, M. H., et al. (2014). Dengue viral protease interaction with NF-kappaB inhibitor alpha/beta results in endothelial cell apoptosis and hemorrhage development. J. Immunol. 193, 1258-1267. doi: 10.4049/jimmunol.1302675

Liu, S., DeLalio, L. J., Isakson, B. E., and Wang, T. T. (2016). AXL-mediated productive infection of human endothelial cells by zika virus. Circ. Res. 119, 1183-1189. doi: 10.1161/CIRCRESAHA.116.309866

Long, X., Li, Y., Qi, Y., Xu, J., Wang, Z., Zhang, X., et al. (2013). XAF1 contributes to dengue virus-induced apoptosis in vascular endothelial cells. FASEB J. 27, 1062-1073. doi: 10.1096/fj.12-213967

Lowe, R., Barcellos, C., Brasil, P., Cruz, O. G., Honório, N. A., Kuper, H., et al. (2018). The zika virus epidemic in brazil: from discovery to future implications. Int. J. Environ. Res. Public Health 15:E96. doi: 10.3390/ijerph150 10096

Lunardi, C., Dolcino, M., Peterlana, D., Bason, C., Navone, R., Tamassia, N., et al. (2007). Endothelial cells' activation and apoptosis induced by a subset of antibodies against human cytomegalovirus: relevance to the pathogenesis of atherosclerosis. PLoS One 2:e473. doi: 10.1371/journal.pone.0000473

Macnamara, F. N. (1954). Zika virus: a report on three cases of human infection during an epidemic of jaundice in Nigeria. Trans. R. Soc. Trop. Med. Hyg. 48, 139-145. doi: 10.1016/0035-9203(54)90006-1

Mansuy, J. M., Dutertre, M., Mengelle, C., Fourcade, C., Marchou, B., Delobel, P., et al. (2016a). "Zika virus: high infectious viral load in semen, a new sexually transmitted pathogen?". Lancet Infect. Dis. 16:405. doi: 10.1016/s1473-3099(16) 00138-9

Mansuy, J. M., Suberbielle, E., Chapuy-Regaud, S., Mengelle, C., Bujan, L., and Marchou, B. (2016b). Zika virus in semen and spermatozoa. Lancet Infect. Dis. $16,1106-1107$.

Martinon, F., Burns, K., and Tschopp, J. (2002). The inflammasome: a molecular platform triggering activation of inflammatory caspases and processing of proIL-beta. Mol. Cell. 10, 417-426.

Matheron, S., d'Ortenzio, E., Leparc-Goffart, I., Hubert, B., de Lamballerie, X., and Yazdanpanah, Y. (2016). Long-lasting persistence of zika virus in semen. Clin. Infect. Dis. 63, 1264.

McCarthy, M. (2016). Zika virus was transmitted by sexual contact in Texas, health officials report. BMJ 352: i720. doi: 10.1136/bmj.i720

Medlock, J. M., Hansford, K. M., Schaffner, F., Versteirt, V., Hendrickx, G., Zeller, H., et al. (2012). A review of the invasive mosquitoes in Europe: ecology, public health risks, and control options. Vector Borne Zoonotic Dis. 12, 435-447. doi: 10.1089/vbz.2011.0814

Meertens, L., Labeau, A., Dejarnac, O., Cipriani, S., Sinigaglia, L., Bonnet-Madin, L., et al. (2017). Axl mediates ZIKA virus entry in human glial cells and modulates innate immune responses. Cell Rep. 18, 324-333. doi: 10.1016/j. celrep.2016.12.045

Michlmayr, D., Andrade, P., Gonzalez, K., Balmaseda, A., and Harris, E. (2017). $\mathrm{CD} 14(+) \mathrm{CD} 16(+)$ monocytes are the main target of Zika virus infection in peripheral blood mononuclear cells in a paediatric study in Nicaragua. Nat. Microbiol. 2, 1462-1470. doi: 10.1038/s41564-017-0035-0 
Miller, L. S., Pietras, E. M., Uricchio, L. H., Hirano, K., Rao, S., Lin, H., et al. (2007). Inflammasome-mediated production of IL -1beta is required for neutrophil recruitment against Staphylococcus aureus in vivo. J. Immunol. 179, 6933-6942. doi: 10.4049/jimmunol.179.10.6933

Miner, J. J., Cao, B., Govero, J., Smith, A. M., Fernandez, E., Cabrera, O. H., et al. (2016). Zika virus infection during pregnancy in mice causes placental damage and fetal demise. Cell 165, 1081-1091. doi: 10.1016/j.cell.2016.05.008

Mladinich, M. C., Schwedes, J., and Mackow, E. R. (2017). Zika virus persistently infects and is basolaterally released from primary human brain microvascular endothelial cells. mBio 8:e0052-17. doi: 10.1128/mBio.00952-17

Moore, C. A., Staples, J. E., Dobyns, W. B., Pessoa, A., Ventura, C. V., Fonseca, E. B., et al. (2017). Characterizing the pattern of anomalies in congenital zika syndrome for pediatric clinicians. JAMA Pediatr. 171, 288-295. doi: 10.1001/ jamapediatrics.2016.3982

Moreira, J., Peixoto, T. M., Siqueira, A. M., and Lamas, C. C. (2017). Sexually acquired Zika virus: a systematic review. Clin. Microbiol. Infect. 23, 296-305. doi: $10.1016 /$ j.cmi.2016.12.027

Muller, D. A., and Young, P. R. (2013). The flavivirus NS1 protein: molecular and structural biology, immunology, role in pathogenesis and application as a diagnostic biomarker. Antiviral Res. 98, 192-208. doi: 10.1016/j.antiviral.2013. 03.008

Musso, D., Richard, V., Teissier, A., Stone, M., Lanteri, M. C., Latoni, G., et al. (2017a). Detection of Zika virus RNA in semen of asymptomatic blood donors. Clin. Microbiol. Infect. 23:e1001. doi: 10.1016/j.cmi.2017.07.006

Musso, D., Rouault, E., Teissier, A., Lanteri, M. C., Zisou, K., Broult, J., et al. (2017b). Molecular detection of Zika virus in blood and RNA load determination during the French Polynesian outbreak. J. Med. Virol. 89, 15051510. doi: $10.1002 /$ jmv. 24735

Musso, D., Roche, C., Nhan, T. X., Robin, E., Teissier, A., and Cao-Lormeau, V. M. (2015). Detection of Zika virus in saliva. J. Clin. Virol. 68, 53-55. doi: 10.1016/j.jcv.2015.04.021

Nem de Oliveira Souza, I., Frost, P. S., França, J. V., Nascimento-Viana, J. B., Neris, R. L. S., Freitas, L., et al. (2018). Acute and chronic neurological consequences of early-life Zika virus infection in mice. Sci. Transl. Med. 10:eaar2749. doi: 10.1126/scitranslmed.aar2749

Nicastri, E., Castilletti, C., Liuzzi, G., Iannetta, M., Capobianchi, M. R., and Ippolito, G. (2016). Persistent detection of Zika virus RNA in semen for six months after symptom onset in a traveller returning from Haiti to Italy, February 2016. Euro. Surveill. 21:30314. doi: 10.2807/1560-7917.ES.2016.21.32. 30314

Nowakowski, T. J., Pollen, A. A., Di Lullo, E., Sandoval-Espinosa, C., Bershteyn, M., and Kriegstein, A. R. (2016). Expression analysis highlights AXL as a candidate zika virus entry receptor in neural stem cells. Cell Stem Cell 18, 591-596. doi: 10.1016/j.stem.2016.03.012

PAHO (2016). Zika Cumulative Cases. Available at: https://www.paho.org/hq/ index.php?option=com_content\&view $=$ article $\&$ id $=12390 \&$ Itemid $=42090 \&$ lang=en

PAHO (2017). Regional Zika Epidemiological Update (Americas) August 25, 2017. Available at: https://www.paho.org/hq/index.php?option=com_content\&view= article\&id $=11599 \&$ Itemid $=41691$ \&lang=en

Pan American Health Organization World Health Organization (2016). Epidemiological Update: Neurological Syndrome, Congenital Anomalies, and Zika Virus Infection. Washington, D.C: Pan American Health Organization; World Health Organization.

Papa, M. P., Meuren, L. M., Coelho, S. V. A., Lucas, C. G. O., Mustafá, Y. M., and Lemos Matassoli, F. (2017). Zika virus infects, activates, and crosses brain microvascular endothelial cells, without barrier disruption. Front. Microbiol. 8:2557. doi: 10.3389/fmicb.2017.02557

Paz-Bailey, G., Rosenberg, E. S., and Sharp, T. M. (2017). Persistence of Zika virus in body fluids - preliminary report. N. Engl. J. Med. 379, 1234-1243. doi: 10.1056/nejmoa1613108

Peng, H., Liu, B., Yves, T. D., He, Y., Wang, S., Tang, H., et al. (2018). Zika virus induces autophagy in human umbilical vein endothelial cells. Viruses 10:E259. doi: 10.3390/v10050259

Pereira, L., Maidji, E., McDonagh, S., Genbacev, O., and Fisher, S. (2003). Human cytomegalovirus transmission from the uterus to the placenta correlates with the presence of pathogenic bacteria and maternal immunity. J. Virol. 77, 13301-13314. doi: 10.1128/jvi.77.24.13301-13314.2003
Petersen, L. R., Jamieson, D. J., Powers, A. M., and Honein, M. A. (2016). Zika Virus. N. Engl. J. Med. 374, 1552-1563.

Prasad, V. M., Miller, A. S., Klose, T., Sirohi, D., Buda, G., Jiang, W., et al. (2017). Structure of the immature Zika virus at 9 A resolution. Nat. Struct. Mol. Biol. 24, 184-186. doi: 10.1038/nsmb.3352

Prisant, N., Bujan, L., Benichou, H., Hayot, P. H., Pavili, L., Lurel, S., et al. (2016). Zika virus in the female genital tract. Lancet Infect. Dis. 16:1000.

Quicke, K. M., Bowen, J. R., Johnson, E. L., McDonald, C. E., Ma, H., O’Neal, J. T., et al. (2016). Zika virus infects human placental macrophages. Cell Host Microbe 20, 83-90. doi: 10.1016/j.chom.2016.05.015

Ray, D., Shah, A., Tilgner, M., Guo, Y., Zhao, Y., Dong, H., et al. (2006). West Nile virus $5^{\prime}$-cap structure is formed by sequential guanine N-7 and ribose $2^{\prime}$-O methylations by nonstructural protein 5. J. Virol. 80, 8362-8370. doi: 10.1128/jvi.00814-06

Retallack, H., Di Lullo, E., Arias, C., Knopp, K. A., Laurie, M. T., SandovalEspinosa, C., et al. (2016). Zika virus cell tropism in the developing human brain and inhibition by azithromycin. Proc. Natl. Acad. Sci. U.S.A. 113, 14408-14413. doi: $10.1073 /$ pnas.1618029113

Reynolds, M. R., Jones, A. M., Petersen, E. E., Lee, E. H., Rice, M. E., Bingham, A., et al. (2017). Vital signs: update on zika virus-associated birth defects and evaluation of all U.S. infants with congenital zika virus exposure - U.S. Zika pregnancy registry, 2016. MMWR Morb. Mortal Wkly. Rep. 66, 366-373. doi: 10.15585/mmwr.mm6613e1

Ribeiro, G. S., Kikuti, M., Tauro, L. B., Nascimento, L. C. J., Cardoso, C. W., Campos, G. S., et al. (2018). "Does immunity after Zika virus infection crossprotect against dengue?”. Lancet Glob. Health 6, e140-e141.

Richard, A. S., Shim, B. S., Kwon, Y. C., Zhang, R., Otsuka, Y., Schmitt, K., et al. (2017). AXL-dependent infection of human fetal endothelial cells distinguishes Zika virus from other pathogenic flaviviruses. Proc. Natl. Acad. Sci. U.S.A. 114, 2024-2029. doi: 10.1073/pnas.1620558114

Rigau-Pérez, J. G., Clark, G. G., Gubler, D. J., Reiter, P., Sanders, E. J., and Vorndam, A. V. (1998). Dengue and dengue haemorrhagic fever. Lancet 352, 971-977.

Roach, T., and Alcendor, D. J. (2017). Zika virus infection of cellular components of the blood- retinal barriers: implications for viral associated congenital ocular disease. J. Neuroinflammation 14:43. doi: 10.1186/s12974-017-0824-7

Roby, J. A., Setoh, Y. X., Hall, R. A., and Khromykh, A. A. (2015). Post-translational regulation and modifications of flavivirus structural proteins. J. Gen. Virol. 96(Pt 7), 1551-1569. doi: 10.1099/vir.0.00 0097

Rodrigues, S. F., and Granger, D. N. (2015). Blood cells and endothelial barrier function. Tissue Barriers 3:e978720. doi: 10.4161/21688370.2014.978720

Roze, B., Najioullah, F., Fergé, J. L., Apetse, K., Brouste, Y., Cesaire, R., et al. (2016). Zika virus detection in urine from patients with Guillain- Barre syndrome on Martinique, January 2016. Euro. Surveill. 21:30154. doi: 10.2807/1560-7917.ES. 2016.21.9.30154

Roze, B., Najioullah, F., Fergé, J. L., Dorléans, F., Apetse, K., Barnay, J. L., et al. (2017). Guillain-barre syndrome associated with zika virus infection in martinique in 2016: a prospective study. Clin. Infect. Dis. 65, 1462-1468. doi: $10.1093 / \mathrm{cid} / \mathrm{cix} 588$

Sahoo, M., Jena, L., Daf, S., and Kumar, S. (2016). Virtual screening for potential inhibitors of NS3 protein of zika virus. Genomics Inform. 14, 104-111.

Sansonetti, P. J., Phalipon, A., Arondel, J., Thirumalai, K., Banerjee, S., Akira, S., et al. (2000). Caspase-1 activation of IL-1beta and IL-18 are essential for Shigella flexneri-induced inflammation. Immunity 12, 581-590. doi: 10.1016/s10747613(00)80209-5

Schlesinger, R. W., Bradshaw, G. L., Barbone, F., Reinacher, M., Rott, R., and Husak, P. (1989). Role of hemagglutinin cleavage and expression of M1 protein in replication of $\mathrm{A} / \mathrm{WS} / 33, \mathrm{~A} / \mathrm{PR} / 8 / 34$, and WSN influenza viruses in mouse brain. J. Virol. 63, 1695-1703.

Schuler-Faccini, L., Ribeiro, E. M., Feitosa, I. M., Horovitz, D. D., Cavalcanti, D. P., Pessoa, A., et al. (2016). Possible association between zika virus infection and microcephaly - Brazil, 2015. MMWR Morb. Mortal. Wkly. Rep. 65, 59-62. doi: 10.15585/mmwr.mm6503e2

Scott, T. W., and Takken, W. (2012). Feeding strategies of anthropophilic mosquitoes result in increased risk of pathogen transmission. Trends Parasitol. 28, 114-121. doi: 10.1016/j.pt.2012.01.001

Shao, Q., Herrlinger, S., Yang, S. L., Lai, F., Moore, J. M., Brindley, M. A., et al. (2016). Zika virus infection disrupts neurovascular development and results 
in postnatal microcephaly with brain damage. Development 143, 4127-4136. doi: 10.1242/dev.143768

Sirohi, D., Chen, Z., Sun, L., Klose, T., Pierson, T. C., Rossmann, M. G., et al. (2016). The 3.8 A resolution cryo-EM structure of Zika virus. Science 352, 467-470. doi: $10.1126 /$ science.aaf5316

Souza, W. V., Albuquerque, M. F. P. M., Vazquez, E., Bezerra, L. C. A., Mendes, A. D. C. G., Lyra, T. M., et al. (2018). Microcephaly epidemic related to the Zika virus and living conditions in Recife, Northeast Brazil. BMC Public Health 18:130. doi: 10.1186/s12889-018-5039-Z

Stettler, K., Beltramello, M., Espinosa, D. A., Graham, V., Cassotta, A., Bianchi, S., et al. (2016). Specificity, cross-reactivity, and function of antibodies elicited by Zika virus infection. Science 353, 823-826. doi: 10.1126/science.aaf8505

Swaminathan, S., Schlaberg, R., Lewis, J., Hanson, K. E., and Couturier, M. R. (2016). Fatal Zika virus infection with secondary nonsexual transmission. N. Engl. J. Med. 375, 1907-1909. doi: 10.1056/nejmc1610613

Szaba, F. M., Tighe, M., Kummer, L. W., Lanzer, K. G., Ward, J. M., Lanthier, P., et al. (2018). Zika virus infection in immunocompetent pregnant mice causes fetal damage and placental pathology in the absence of fetal infection. PLoS Pathog. 14:e1006994. doi: 10.1371/journal.ppat.1006994

Tabata, T., Petitt, M., Puerta-Guardo, H., Michlmayr, D., Wang, C., Fang-Hoover, J., et al. (2016). Zika virus targets different primary human placental cells, suggesting two routes for vertical transmission. Cell Host Microbe 20, 155-166. doi: 10.1016/j.chom.2016.07.002

Tang, W. W., Young, M. P., Mamidi, A., Regla-Nava, J. A., Kim, K., and Shresta, S. (2016). A mouse model of zika virus sexual transmission and vaginal viral replication. Cell Rep. 17, 3091-3098. doi: 10.1016/j.celrep.2016.11.070

Triunfol, M. (2016). Microcephaly in Brazil: confidence builds in Zika connection. Lancet Infect Dis. 16, 527-528. doi: 10.1016/s1473-3099(16)30015-9

Turmel, J. M., Abgueguen, P., Hubert, B., Vandamme, Y. M., Maquart, M., Le Guillou-Guillemette, H., et al. (2016). Late sexual transmission of Zika virus related to persistence in the semen. Lancet 387:2501. doi: 10.1016/s01406736(16)30775-9

Uraki, R., Jurado, K. A., Hwang, J., Szigeti-Buck, K., Horvath, T. L., Iwasaki, A., et al. (2017). Fetal growth restriction caused by sexual transmission of zika virus in mice. J. Infect. Dis. 215, 1720-1724. doi: 10.1093/infdis/jix204

Valbuena, G., and Walker, D. H. (2006). The endothelium as a target for infections. Annu. Rev. Pathol. 1, 171-198. doi: 10.1146/annurev.pathol.1.110304.100031

Venturi, G., Zammarchi, L., Fortuna, C., Remoli, M. E., Benedetti, E., Fiorentini, C., et al. (2016). An autochthonous case of Zika due to possible sexual transmission, Florence, Italy, 2014. Euro. Surveill. 21:30148. doi: 10.2807/1560-7917.ES.2016. 21.8.30148

Vonk, A. G., Netea, M. G., van Krieken, J. H., Iwakura, Y., van der Meer, J. W., and Kullberg, B. J. (2006). Endogenous interleukin (IL)-1 alpha and IL-1 beta are crucial for host defense against disseminated candidiasis. J. Infect. Dis. 193, 1419-1426. doi: 10.1086/503363

Wan, C. K., He, C., Sun, L., Egwuagu, C. E., and Leonard, W. J. (2016). Cutting edge: IL-1 receptor signaling is critical for the development of autoimmune uveitis. J. Immunol. 196, 543-546. doi: 10.4049/jimmunol.1502080

Wang, L., Manji, G. A., Grenier, J. M., Al-Garawi, A., Merriam, S., Lora, J. M., et al. (2002). PYPAF7, a novel PYRIN-containing Apaf1-like protein that regulates activation of NF-kappa B and caspase-1-dependent cytokine processing. J. Biol. Chem. 277, 29874-29880. doi: 10.1074/jbc.m203915200

Wang, Z. Y., Wang, Z., Zhen, Z. D., Feng, K. H., Guo, J., Gao, N., et al. (2017). Axl is not an indispensable factor for Zika virus infection in mice. J. Gen. Virol. 98, 2061-2068. doi: 10.1099/jgv.0.000886
Warrener, P., Tamura, J. K., and Collett, M. S. (1993). RNA-stimulated NTPase activity associated with yellow fever virus NS3 protein expressed in bacteria. J. Virol. 67, 989-996.

Wengler, G., Czaya, G., Färber, P. M., and Hegemann, J. H. (1991). In vitro synthesis of West Nile virus proteins indicates that the amino-terminal segment of the NS3 protein contains the active centre of the protease which cleaves the viral polyprotein after multiple basic amino acids. J. Gen. Virol. 72(Pt 4), 851-858. doi: 10.1099/0022-1317-72-4-851

WHO (2018). Infant and Young Child Feeding. Geneva: WHO.

Wijdicks, E. F., and Klein, C. J. (2017). Guillain-barre syndrome. Mayo Clin. Proc. 92, 467-479. doi: 10.1016/j.mayocp.2016.12.002

Winkler, C. W., Myers, L. M., Woods, T. A., Messer, R. J., Carmody, A. B., McNally, K. L., et al. (2017a). Adaptive immune responses to zika virus are important for controlling virus infection and preventing infection in brain and testes. J. Immunol. 198, 3526-3535. doi: 10.4049/jimmunol.1601949

Winkler, C. W., Woods, T. A., Rosenke, R., Scott, D. P., Best, S. M., and Peterson, K. E. (2017b). Sexual and vertical transmission of zika virus in anti-interferon receptor-treated Rag1-deficient mice. Sci. Rep. 7:7176. doi: 10.1038/s41598017-07099-7

Woollard, S. M., Olwenyi, O. A., Dutta, D., Dave, R. S., Mathews, S., Gorantla, S., et al. (2018). Preliminary studies on immune response and viral pathogenesis of Zika Virus in Rhesus Macaques. Pathogens 7:E70. doi: 10.3390/ pathogens 7030070

Wu, X., Liu, X., Koul, S., Lee, C. Y., Zhang, Z., and Halmos, B. (2014). AXL kinase as a novel target for cancer therapy. Oncotarget 5, 9546-9563.

Xia, H., Luo, H., Shan, C., Muruato, A. E., Nunes, B. T. D., Medeiros, D. B. A., et al. (2018). An evolutionary NS1 mutation enhances Zika virus evasion of host interferon induction. Nat. Commun. 9:414. doi: 10.1038/s41467-01702816-2

Yockey, L. J., Varela, L., Rakib, T., Khoury-Hanold, W., Fink, S. L., Stutz, B., et al. (2016). Vaginal exposure to zika virus during pregnancy leads to fetal brain infection. Cell 166, 1247.e4-1256.e4. doi: 10.1016/j.cell.2016. 08.004

Yokoyama, S., and Starmer, W. T. (2017). Possible roles of new mutations shared by Asian and American Zika viruses. Mol. Biol. Evol. 34, 525-534. doi: 10.1093/ molbev/msw270

Yuan, L., Huang, X. Y., Liu, Z. Y., Zhang, F., Zhu, X. L., Yu, J. Y., et al. (2017). A single mutation in the prM protein of Zika virus contributes to fetal microcephaly. Science 358, 933-936. doi: 10.1126/science.aam7120

Yusof, R., Clum, S., Wetzel, M., Murthy, H. M., and Padmanabhan, R. (2000). Purified NS2B/NS3 serine protease of dengue virus type 2 exhibits cofactor NS2B dependence for cleavage of substrates with dibasic amino acids in vitro. J. Biol. Chem. 275, 9963-9969. doi: 10.1074/jbc.275.14.9963

Conflict of Interest Statement: The authors declare that the research was conducted in the absence of any commercial or financial relationships that could be construed as a potential conflict of interest.

Copyright (c) 2019 Khaiboullina, Ribeiro, Uppal, Martynova, Rizvanov and Verma. This is an open-access article distributed under the terms of the Creative Commons Attribution License (CC BY). The use, distribution or reproduction in other forums is permitted, provided the original author(s) and the copyright owner(s) are credited and that the original publication in this journal is cited, in accordance with accepted academic practice. No use, distribution or reproduction is permitted which does not comply with these terms. 